\title{
Expression, structure and function analysis of the sperm-oocyte fusion genes Juno and Izumo1 in sheep (Ovis aries)
}

Wenping $\mathrm{Hu}^{1}$, Xinlong Dong ${ }^{1}$, Zhilong Tian' ${ }^{1}$ Zhuangbiao Zhang ${ }^{1}$, Jishun Tang ${ }^{1,2}$, Benmeng Liang ${ }^{1}$, Qiuyue Liu $^{1,3^{*}}$ and Mingxing Chu ${ }^{1 *}$

\begin{abstract}
Background: JUNO and IZUMO1 are the first receptor-ligand protein pairs discovered to be essential for spermoocyte fusion; their interaction is indispensable for fertilization.

Methods: PCR was used to clone the full-length DNA sequence of the Juno gene in sheep. The single nucleotide polymorphism (SNP) loci of Juno were genotyped by Sequenom MasSARRAY ${ }^{\circledR}$. PCR combined with rapid amplification of CDNA Ends were used to clone the full-length CDNA sequence of Juno and Izumo1. Reverse transcriptase-PCR (RT-PCR) and real time-quantitative-PCR (RT-qPCR) were used to analyze the genes' expression in tissues of sheep, and single cell RNA-seq was used to analyze the genes' expression in oocytes, granulosa cells and follicular theca of polytocous and monotocous Small Tail Han ewes. Bioinformatics was used to analyze advanced structure and phylogeny of JUNO and IZUMO1 proteins.

Results: The full-length DNA sequence of the Juno gene in sheep was cloned and nine SNPs were screened. We found a significant association between the g.848253 C > A locus of Juno and litter size of Small Tail Han sheep $(P<0.05)$. The full-length cDNA sequence of Juno and Izumol genes from Small Tail Han sheep were obtained. We found a new segment of the lzumol CDS consisting of $35 \mathrm{bp}$, and we confirmed the Izumol gene has 9 exons, not 8. RT-qPCR showed that Juno and Izumo 1 genes were highly expressed in ovarian and testicular tissues, respectively $(P<0.01)$. Single cell RNA-seq showed Juno was specifically expressed in oocytes, but not in granulosa cells or follicular theca, while Izumo1 displayed little to no expression in all three cell types. There was no difference in expression of the Juno gene in oocyte and ovarian tissue in sheep with different litter sizes, indicating expression of Juno is not related to litter size traits. Bioinformatic analysis revealed the g.848253 C > A locus of Juno results in a nonconservative missense point mutation leading to a change from Phe to Leu at position 219 in the amino acid sequence.
\end{abstract}

Conclusions: For the first time, this study systematically analyzed the expression, structure and function of Juno and Izumol genes and their encoded proteins in Small Tail Han sheep, providing the basis for future studies of the regulatory mechanisms of Juno and Izumol genes.

Keywords: Fertilization, Izumo 1, Juno, Sheep, Single cell RNA-seq

\footnotetext{
* Correspondence: qyliu@genetics.ac.cn; mxchu@263.net

'Key Laboratory of Animal Genetics and Breeding and Reproduction of

Ministry of Agriculture and Rural Affairs, Institute of Animal Sciences, Chinese

Academy of Agricultural Sciences, Beijing 100193, China

Full list of author information is available at the end of the article
}

(C) The Author(s). 2021 Open Access This article is licensed under a Creative Commons Attribution 4.0 International License, which permits use, sharing, adaptation, distribution and reproduction in any medium or format, as long as you give appropriate credit to the original author(s) and the source, provide a link to the Creative Commons licence, and indicate if changes were made. The images or other third party material in this article are included in the article's Creative Commons licence, unless indicated otherwise in a credit line to the material. If material is not included in the article's Creative Commons licence and your intended use is not permitted by statutory regulation or exceeds the permitted use, you will need to obtain permission directly from the copyright holder. To view a copy of this licence, visit http://creativecommons.org/licenses/by/4.0/ The Creative Commons Public Domain Dedication waiver (http://creativecommons.org/publicdomain/zero/1.0/) applies to the data made available in this article, unless otherwise stated in a credit line to the data. 


\section{Introduction}

Sexual reproduction results in completely new individuals and ensures continuous reproduction for most eukaryotes. Fertilization - the encounter and combination of two morphologically distinct male (sperm) and female (oocyte) germ cells - is the most important part of mammalian sexual reproduction. These two haploid germ cells meet in the reproductive tube of the mother (e.g., the oviduct in mammals), recognize each other, fuse and become a diploid that develops into a genetically unique organism.

Until recently, sperm-oocyte fusion has been a mysterious phenomenon. In 2005, Inoue et al. identified a sperm surface protein, IZUMO1, that is essential for binding to oocytes [1]. Each of the four members of the gene family, Izumo1, Izumo2, Izumo3, and Izumo4, share a homologous N-terminal "IZUMO" domain [2].

It took more than 9 years to find the cognate receptor of IZUMO1 on the oocyte cell surface. In the meantime, several receptor proteins were explored as potential recognition factors [3], such as CD9 [4-7]. Although CD9 and IZUMO1 are both essential for fertilization to occur, CD9 was ruled out because IZUMO1 is capable of binding to both wild-type and CD9 deficient oocytes. In 2014, Bianche et al. devised a new technique to identify low-affinity extracellular interactions that allowed them to uncover the IZUMO1 receptor - a GPI-anchored protein called folate receptor 4 (Folr4). Because Folr4 turned out to be the sole receptor for IZUMO1 (and was not able to bind folate after all), it was aptly renamed JUNO, after the Roman goddess of marriage [8]. While the IZUMO1-JUNO adhesion complex is the first ligand-receptor pair known to be essential for fertilization, a recent study found a new protein involved in sperm-oocyte membrane fusion during fertilization, Fertilization Influencing Membrane Protein (FIMP) [9].

The recognition and binding of IZUMO1 and JUNO is an adhesion event, conserved in both human and mouse oocytes [10]. Within 40 min of the first adhesion event between JUNO and IZUMO1, JUNO is completely absent from the oocyte cell surface. During this time, JUNO is packed into vesicles and released outside of the oocyte membrane where it quickly neutralizes other activated sperm. This shedding mechanism ensures the oocyte can only fuse with one sperm, as polyspermy results in a nonviable embryo [11]. Because of the key roles of IZUMO1 and JUNO, their sensitivity is likely to affect the pregnancy rate and sperm-oocyte recognition efficiency of mammals, and overall affect the fecundity of mammals.

The interaction between IZUMO1 and JUNO is conserved in both mammals (e.g., human, mouse, and pig) and nonmammals (e.g., opossum) [8]. Most research on IZUMO1 and JUNO has been conducted in human [12] and mouse, whereas their relevance in sheep reproduction is rarely investigated. There are some research about Izumo1 in pig [13] and sheep [14]. However, research to date has not addressed JUNO in sheep. In this study, the single nucleotide polymorphisms (SNP) of the Juno gene in sheep were identified and genotyped; the association between each SNP and litter size was analyzed. The fulllength cDNA sequence of Juno and Izumo1 were cloned from the ovary of Small Tail Han sheep using PCR and RACE technologies, and bioinformatic analyses were carried out to characterize the genes and their hypothetical protein products. The expression of Juno and Izumo1 genes in various tissues were measured with RT-PCR and RT-qPCR. This study provides the basis for further revealing the function and expression regulation of the Juno and Izumo1 genes in sheep, and for further studying the molecular mechanisms regulating reproduction in sheep.

\section{Materials and methods \\ Sequence polymorphism of the sheep Juno gene and its association with litter size Materials and main reagents}

A total of 760 sheep were selected, including 380 Small Tail Han sheep, a polytocous sheep breed with litter size records, and a total of 380 sheep consisting of five monotocous breeds. There were 100 Sunite sheep, 80 Tan sheep, 39 Suffolk sheep, 30 Dorper sheep and 131 Prairie Tibetan sheep. From each sheep, $10 \mathrm{~mL}$ of jugular vein blood was collected and stored at $4{ }^{\circ} \mathrm{C}$ after anticoagulation with EDTA.

Small Tail Han sheep were from Chenglian Small Tail Han Sheep Breeding Farm (Yuncheng County, Shandong Province, China) and Shengyi Animal Husbandry Co., Ltd. (Zhangqiu, Shandong Province, China). Sunite sheep were from Minyang Husbandry Co., Ltd. (Wulate Middle Banner in Bayannaoer, Inner Mongolia, China). Tan sheep were from Ningxia Shuomu Yanchi Tan Sheep Breeding Co., Ltd. (Yanchi County, Ningxia, China). Suffolk sheep and Dorper sheep were from Beijing Aoxin Husbandry Co., Ltd. (Beijing, China), and Prairie Tibetan sheep were from Dangxiong County, Tibet, China.

2× Taq PCR Master Mix (MT201-01) was bought from Beijing Biomed Gene Technology Co., Ltd. (Beijing, China). TaKaRa LA Taq ${ }^{\circ}$ with GC Buffer (RR02AG), TaKaRa MiniBEST Agarose Gel DNA Extraction Kit Ver.4.0 (9762), E. coli DH5 $\alpha$ competent cells (9057), and $\mathrm{pMD}^{\mathrm{rm}} 18-\mathrm{T}$ Vector Cloning Kit (6011) were from Takara Bio Co., Ltd. (Dalian, China).

\section{DNA extraction and detection}

DNA was extracted with a blood genomic DNA extraction kit (Tiangen Biotech Co., LTD, Beijing), according to the manufacturer's instructions. The purity and 
concentration of DNA were detected with a NanoDrop 2000 spectrophotometer (Thermo Scientific), and genomic DNA integrity was detected by $1.5 \%$ agarose gel electrophoresis. Samples were only considered acceptable if the $260 \mathrm{~nm}$ to $280 \mathrm{~nm}$ ratio was in the range of $1.8-2.0$, the concentration was above $30 \mathrm{ng} / \mathrm{mL}$ and the electrophoretic bands were qualified (Fig. S1).

\section{Primer design and synthesis}

According to the published genome sequence of the sheep Juno gene (GenBank accession: NC_019472.2), three primers were designed using Primer Premier 5.0 software. To improve the accuracy of sequencing, primers were designed in segments. The primers were synthesized by Beijing Tianyihuiyuan Biotechnology Co., Ltd. Primer sequence, product size and annealing temperature are shown in Table S1.

\section{DNA amplification}

Using the extracted blood genomic DNA as templates, the target gene DNA was amplified using the TaKaRa high fidelity LA Taq enzyme system. Each $20 \mu \mathrm{L}$ reaction contained $0.25 \mu \mathrm{L}$ TaKaRa LA Taq $(5 \mathrm{U} / \mu \mathrm{L}), 10 \mu \mathrm{L} 2 \times$ GC Buffer I ( $5 \mathrm{mmol} / \mathrm{L} \mathrm{Mg}^{2+}$ Plus), $3 \mu \mathrm{L}$ dNTPs $(2.5$ $\mathrm{mmol} / \mathrm{L}$ of each dNTP), $4.25 \mu \mathrm{L}$ RNase-free $\mathrm{ddH}_{2} \mathrm{O}$, $0.5 \mu \mathrm{L}$ forward primer (Table S1), $0.5 \mu \mathrm{L}$ reverse primer and $1.5 \mu \mathrm{L}$ blood genomic DNA. The PCR program started with denaturation at $95^{\circ} \mathrm{C}$ for $5 \mathrm{~min}$, and was followed by 35 cycles of denaturation at $95^{\circ} \mathrm{C}$ for $30 \mathrm{~s}$, annealing at $66^{\circ} \mathrm{C}$ for $45 \mathrm{~s}$ and extension at $72^{\circ} \mathrm{C}$ for 2 min, followed by a final extension at $72^{\circ} \mathrm{C}$ for $8 \mathrm{~min}$.

After the reaction, the PCR product was detected by $1.5 \%$ agarose gel electrophoresis, and the positive amplification products were cloned and sequenced (Sangon Biotech Co., Ltd., Shanghai, China).

\section{SNP loci screening}

DNA sequence comparisons and analysis were conducted with DNAMAN 6.0, and peak map judgment was conducted with Chromas Pro 1.5. The DNA sequence of Juno was compared with re-sequencing data from our laboratory consisting of 100 individual sheep from 10 different breeds [15]. A loci was considered an SNP if the proportion of different bases at the same locus were more than $30 \%$ SNP loci were screened to identify synonymous and non-synonymous mutations.

\section{Genotyping}

Three pairs of primers were used to screen SNP loci of the Juno gene in 60 samples of Small Tail Han sheep and Sunite sheep. Single bands, signifying good specificity in PCR amplification were sequenced bidirectionally. The loci with clear sequence peaks were used for SNP statistics. The SNP loci of the Juno gene were genotyped in the blood DNA samples of Small Tail Han sheep, Sunite sheep, Tan sheep, Suffolk sheep, Dorper sheep and Prairie Tibetan sheep with the iPLEX ${ }^{\mathrm{ma}}$ assay using the MassARRAY ${ }^{\circ}$ genotyping system (Sequenom, San Diego, CA, USA). The experimental steps were carried out following the instrument operating guidelines.

\section{Statistical analysis}

Popgene 32 (version 3.2) and PIC-CALC were used to process the results of genotyping and calculate the heterozygosity (HE) and the polymorphism information content (PIC). The genotype and gene frequencies of SNP loci in polytocous and monotocous breeds were subjected to a chi-square test using SPSS 18.0, and the correlation between genotype frequencies and litter size was analyzed. The relevance analysis model was:

$$
\mathrm{y}_{\mathrm{ijkl}}=\mu+\mathrm{G}_{\mathrm{i}}+\mathrm{P}_{\mathrm{j}}+\mathrm{S}_{\mathrm{k}}+\mathrm{e}_{\mathrm{ijkl}}
$$

Where, $y$ is the phenotypic value of the litter size, $\mu$ is the population mean, $G_{i}$ is the genotype effect, $P_{j}$ is parity effect, $s k$ is the field effect, and $e_{i j k l}$ is the random residual effect of each observation. Assuming each observation was independent, we used a $\mathrm{N}\left(0, \sigma^{2}\right)$ distribution.

\section{cDNA cloning and differential expression analysis of Juno and Izumo 1 genes in sheep Materials and main reagents}

Three male Small Tail Han sheep, three female Small Tail Han sheep, three male Sunite sheep, and three female Sunite sheep in good health and with the same bodyweight and sexual maturity were selected for euthanasia,sheep and Sunite sheep for euthanasia. Sixteen types of tissues, including gonadal (testis, epididymis, sperm duct/ovary, uterus, oviduct), pineal gland, hypothalamus, pituitary, cerebellum, heart, liver, spleen, lung, kidney, skeletal muscle, duodenum, subcutaneous abdominal fat and adrenal gland were collected quickly and put into a pre-labeled $1.8 \mathrm{~mL}$ RNase-Free cryopreservation tube. The tubes were immediately placed in liquid nitrogen and transferred to a cryogenic refrigerator $\left(-80^{\circ} \mathrm{C}\right)$ for storage.

TRIZOL $^{\circ}$ LS Reagent and SYBR ${ }^{\circ}$ Safe DNA gel stain (S33102) were bought from Invitrogen, ThermoFisher Scientific, CN. Total RNA Extraction Kit for Animal Tissues (DP431) was bought from Tiangen Biotech Co., LTD (Beijing). 2× Taq PCR Master Mix (MT201-01) was bought from Biomed Gene Technology Co., LTD. TaKaRa LA Taq ${ }^{\circ}$ with GC Buffer (RR02AG), PrimeScript $^{\text {Ti }}$ RT reagent kit (Perfect Real Time) (RR037A), TaKaRa MiniBEST Agarose Gel DNA Extraction Kit Ver.4.0 (9762), SMARTer RACE 5'/3'Kit (634858), E. coli DH5 $\alpha$ competent cells (9057), pMD ${ }^{\mathrm{ms}} 18-\mathrm{T}$ Vector 
Cloning Kit (6011), PrimeScript ${ }^{\circ}$ RT reagent Kit Perfect Real-Time (RR037A) and SYBR ${ }^{\circ}$ Premix Ex Taq ${ }^{\text {ma }}$ II (Tli RNaseH Plus) (RR820A) were bought from Takara Bio Co., Ltd. (Dalian, China).

\section{cDNA cloning of Juno and Izumo1 genes}

\section{- Extraction of total RNA from samples}

Samples from different parts of each sheep were ground in liquid nitrogen, and then total RNA was extracted with the Total RNA Extraction Kit for Animal Tissues (DP431). RNA integrity was assessed by $1 \%$ agarose gel electrophoresis, and RNA concentration and purity were measured by nanodrop spectrophotometry. Only RNA samples displaying a $260 \mathrm{~nm} / 280 \mathrm{~nm}$ ratio between 1.8 and 2 were used in this study. The product was stored in $\mathrm{a}-80^{\circ} \mathrm{C}$ cryogenic freezer until further use.

- Coding sequence (CDS) cloning of Juno and Izumo1 genes

Total RNA of the ovaries and testes of Small Tail Han sheep was subjected to RT-PCR with the PrimeScript ${ }^{\mathrm{mm}}$ RT reagent kit. The reverse transcription products were stored at $-20^{\circ} \mathrm{C}$. According to the predicted Juno and Izumo1 genes sequences (NCBI reference sequences: XM_015100756.1 and NM_001164492.1), the amplification primers of Juno and Izumo1 were designed with Primer Premier 5.0 software (Table S2).

The cDNA from ovaries and testes of Small Tail Han sheep obtained by RT-PCR was used as templates to clone the Juno and Izumo1 genes using the TaKaRa LA Taq with GC Buffer (RR02AG) enzyme system. Each $20 \mu \mathrm{L}$ reaction contained $1 \mu \mathrm{L}$ cDNA, $0.5 \mu \mathrm{L}$ forward primer (Table S2), $0.5 \mu \mathrm{L}$ reverse primer, $10 \mu \mathrm{L} 2 \times$ Taq PCR Master Mix and $8 \mu \mathrm{L} \mathrm{ddH}_{2} \mathrm{O}$. The PCR program started with denaturation at $95^{\circ} \mathrm{C}$ for $5 \mathrm{~min}$, followed by 35 cycles of denaturation at $95^{\circ} \mathrm{C}$ for $30 \mathrm{~s}$, annealing at $62{ }^{\circ} \mathrm{C}$ for $30 \mathrm{~s}$ and extension at $72{ }^{\circ} \mathrm{C}$ for $5 \mathrm{~s}$, followed by a final extension at $72{ }^{\circ} \mathrm{C}$ for $8 \mathrm{~min}$. The amplified products were detected by $1.5 \%$ agarose gel electrophoresis. The target fragments were recovered using the TaKaRa MiniBEST Agarose Gel DNA Extraction Kit Ver.4.0 (9762), ligated into a pMD18-T (TaKaRa) vector, and transformed into DH5 $\alpha$ competent cells. Ampicillin resistant colonies were screened by colony PCR and DNA fragments were sent to Sangon Biotech Co., Ltd. (Shanghai) for sequencing.

- 3' $15^{\prime}$ Rapid amplification of cDNA ends (RACE) of Juno and Izumo1 cDNA
Total RNA of ovaries and testes of Small Tail Han sheep were used as templates, and a SMARTer RACE $5^{\prime} / 3^{\prime}$ Kit was used for reverse transcription. According to the sequence of the CDS region obtained by sequencing, $5^{\prime}$ and 3' RACE specific primers were designed according to the requirements of the SMARTer RACE 5'/3' Kit. Using the reversed first chain of $3^{\prime}$ RACE and $5^{\prime}$ RACE as templates, the $3^{\prime}$ and $5^{\prime}$ ends of the Juno and Izumo1 genes from sheep were amplified by Touch Down PCR using specific primers 3'GSP and 5'GSP, and a universal primer UPM (Table S2).

\section{Expression of Juno and Izumo1 genes in different tissues}

\section{- RT-PCR of Juno and Izumo1 genes}

Using cDNA obtained from 16 tissues of Small Tail Han sheep and Sunite sheep as templates, Juno-RT primers, Izumo1-RT primers and reference gene $(\beta$ actin) primers, PCR amplification was conducted. Each $20 \mu \mathrm{L}$ reaction consisted of $10 \mu \mathrm{L} 2 \times$ Taq PCR Master Mix, $8 \mu \mathrm{L} \mathrm{ddH}_{2} \mathrm{O}, 0.5 \mu \mathrm{L}$ forward primer, $0.5 \mu \mathrm{L}$ reverse primer and $1 \mu \mathrm{L}$ cDNA. The PCR program began with denaturation at $95^{\circ} \mathrm{C}$ for $5 \mathrm{~min}$, followed by 25 cycles of denaturation at $95^{\circ} \mathrm{C}$ for $30 \mathrm{~s}$, annealing at $62^{\circ} \mathrm{C}$ for $30 \mathrm{~s}$ and extension at $72^{\circ} \mathrm{C}$ for $5 \mathrm{~s}$, followed by a final extension at $72{ }^{\circ} \mathrm{C}$ for $8 \mathrm{~min}$. The amplified products were analyzed by agarose gel electrophoresis. The quality of the cDNA obtained from reverse transcription was amplified with the primers of the reference gene $\beta$-actin to verify that it could be used for subsequent experiments.

\section{- RT-qPCR of the Juno and Izumo1 genes in sheep}

Using cDNA obtained from 16 tissues of Small Tail Han sheep and Sunite sheep as templates, RT-qPCR was conducted. Each $20 \mu \mathrm{L}$ reaction contained $10 \mu \mathrm{L}$ SYBR Premix Ex Taq II, 6.4 $\mu \mathrm{L}$ RNase-Free $\mathrm{ddH}_{2} \mathrm{O}, 0.8 \mu \mathrm{L}$ forward primer, $0.8 \mu \mathrm{L}$ reverse primer and $2 \mu \mathrm{L} \mathrm{cDNA}$. The RT-qPCR reaction started with denaturation at $95^{\circ} \mathrm{C}$ for $5 \mathrm{~s}$, followed by 40 cycles of denaturation at $95^{\circ} \mathrm{C}$ for $5 \mathrm{~s}$ and annealing at $60^{\circ} \mathrm{C}$ for $30 \mathrm{~s}$. Each sample was run in triplicate and $\beta$-actin was used as the reference gene. The relative expression of each target gene was calculated with the $2^{-\triangle \Delta C t}$ method. The data were analyzed with the statistical software SPSS 18.0, and the statistical data were reported as the mean \pm the standard deviation. One-way ANOVA was used to detect differences in expression among different tissues, and the Student's $t$-test was used to compare the differences in expression among the same tissues. $P<0.05$ indicated a significant difference. 
Single cell expression of genes by single cell RNA-seq

Polytocous and monotocous Small Tail Han ewes 3 years of age and with three or higher parity records were selected for single cell gene expression analysis. There were five ewes in each group. A controlled internal drug release (CIDR) device (InterAg company, New Zealand) was used to synchronize the estrus cycles of ewes by administering $300 \mathrm{mg}$ progesterone. After $12 \mathrm{~d}$, the CIDR device was removed. Forty-five $h$ after the CIDR device was removed, the ewes were operated on to collect oocytes, granulosa cells and follicular theca.

The Smart-Seq2 method was used to directly measure gene expression in single cells [16]. A Qubit ${ }^{\circ} 3.0$ Fluorometer (Life Technologies, CA, USA) and an Agilent 2100 High Sensitivity DNA Assay Kit (Agilent Technologies, CA, USA) were used to detect the amplified cDNA concentration and fragment distribution. After that, single-cell cDNA libraries were constructed, and the length distribution of the libraries was detected using an Agilent 2100/LabChip GX Touch. After meeting the length distribution requirements, $\mathrm{qPCR}$ was used to accurately quantify the effective concentration of the cDNA in the libraries (more than $10 \mathrm{nmol} / \mathrm{L}$ ). After the effective concentration of the libraries was qualified, the PE150 double terminal sequencing program was run on the HiSeq sequencing platform for single cell RNA-seq analysis.

Raw reads from Illumina sequencing were filtered to get clean reads for subsequent analyses. With the Hierarchical Graph FM index (HGFM) as the core retrieval method, HiSAT2 was used to filter the RNA-seq data of each sample with the sheep reference genome (Ovis_aries Oar_ v3.1pep_all.fasta). Using StringTie software, RNA-seq comparison results were quickly assembled into transcripts and gene expression levels were predicted.

\section{Bioinformatic analysis of Juno and Izumo1 CDNAs}

The sequencing results were subjected to a BLAST search (NCBI, http://blast.ncbi.nlm.nih.gov/Blast.cgi) to retrieve homologous gene sequences, and DNAMAN software was used to splice the sequences into the fulllength $\mathrm{cDNA}$ sequence of each gene. Open reading frame (ORF) Finder (http://www.ncbi.nlm.nih.gov/ projects/gorf/) was used to determine the ORF and predict the amino acid sequence. ProtParam (http://web. expasy.org/protparam/) was used to predict the physical parameters of each protein such as molecular weight. The hydrophilicity and hydrophobicity of JUNO and IZUMO1 of Small Tail Han sheep were analyzed using ProtScale (https://web.expasy.org/protscale/). Prediction of the secondary structure of each protein and its variants was carried out using PredictProtein (https://www. predictprotein.org/). Phyre2 was used to predict the protein signal peptide, protein transmembrane region and protein tertiary structure. Multiple amino acid sequences were compared using DNAMAN software, and a phylogenetic tree was constructed using the Neighbor-Joining method in MEGA7 software (reference).

\section{Results \\ Polymorphism of the Juno gene in sheep and its association with litter size DNA amplification}

Two complete DNA sequences of the Juno gene in Small Tail Han sheep and Sunite sheep were successfully obtained. The full-length DNA sequences of the Juno gene in Small Tail Han sheep and Sunite sheep were 2167 bp and $2168 \mathrm{bp}$, respectively, and those two sequences were more than 95\% identity. The length of Juno in Small Tail Han sheep and Sunite sheep is similar to the full-length DNA sequence of the Juno gene in Texel sheep (2166 bp, NCBI Reference Sequence: NC_040266.1).

\section{SNPs identification based on whole genome re-sequencing results}

Based on whole genome re-sequencing data from our laboratory consisting of 100 individual sheep from 10 different breeds [15], all SNPs near this region of Juno gene were checked, nine SNP loci of Juno were identified: g.844598A > G, g.846206C > T, g.846268A > G, g.847219G > C, $\quad$ g.847810C $>$ G, $\quad$ g.847814C $>$ T, $\quad$ g.847830T $>C$, g.847927A $>\mathrm{C}$ and g.848253C $>\mathrm{A}$. Among them, eight were in exons and one was in a $5^{\prime}$ UTR. Of the 8 exonic SNPs, five were missense mutations and 3 were synonymous mutations. There were three $\mathrm{T} / \mathrm{C}$ transitions, two $\mathrm{A} / \mathrm{G}$ transitions, two $\mathrm{C} / \mathrm{A}$ transversions and two $\mathrm{G} / \mathrm{C}$ transversions.

\section{Association between SNP loci of Juno and litter size in sheep}

According to the data obtained from genotyping, nine SNP loci were preliminarily screened, and SNP loci with no difference in the allele frequencies between monotocous and polytocous populations were excluded. Seven SNP loci were further analyzed (Table 1). Genotyping showed that there were three genotypes at Juno gene loci g.844598A > G, g.847830T > C, g.847927A > C, g.846268A $>\mathrm{G}$ and g.847810C $>\mathrm{G}$ in monotocous and polytocous breeds, two genotypes (GG and CG) at g.847219G > C in the monotocous breed and three genotypes (GG, CG and CC) in polytocous breed (Table 1). There were $\mathrm{CC}$ and $\mathrm{CA}$ genotypes in monotocous breeds and $\mathrm{CC}, \mathrm{CA}$ and $\mathrm{AA}$ genotypes in polytocous breeds at the g.848253C $>$ A locus. Among them, the genotype frequencies of Juno gene loci g.847830T $>$ C, g.846268A $>\mathrm{G}$ and g.847219G $>\mathrm{C}$ were significantly different between monotocous and polytocous sheep populations $(P<0.01)$. The allele frequencies of Juno gene on loci g.847927A > C, g.846268A $>\mathrm{G}$ and g.847219G $>\mathrm{C}$ 
Table 1 Genotype and allele frequencies of seven SNPs at Juno gene in monotocous and polytocous sheep

\begin{tabular}{|c|c|c|c|c|c|c|c|c|}
\hline Locus & Genotype & $\begin{array}{l}\text { Genotype } \\
\text { frequency in } \\
\text { polytocous } \\
\text { sheep }\end{array}$ & $\begin{array}{l}\text { Genotype frequency } \\
\text { in monotocous sheep }\end{array}$ & $\begin{array}{l}\text { Chi-square } \\
\text { test }(P \text {-value })\end{array}$ & Allele & $\begin{array}{l}\text { Allele frequency } \\
\text { in polytocous } \\
\text { sheep }\end{array}$ & $\begin{array}{l}\text { Allele frequency } \\
\text { in monotocous } \\
\text { sheep }\end{array}$ & $\begin{array}{l}\text { Chi-square } \\
\text { test }(P \text {-value })\end{array}$ \\
\hline \multirow[t]{3}{*}{ g.844598A > G } & GG & 0.31 & 0.36 & 0.28 & G & 0.55 & 0.58 & 0.25 \\
\hline & GA & 0.48 & 0.43 & & A & 0.45 & 0.42 & \\
\hline & AA & 0.21 & 0.21 & & & & & \\
\hline \multirow[t]{3}{*}{ g.847830T > C } & $\mathrm{CC}$ & 0.53 & 0.60 & 0.01 & C & 0.72 & 0.75 & 0.28 \\
\hline & $\mathrm{CT}$ & 0.39 & 0.29 & & T & 0.28 & 0.25 & \\
\hline & $\pi$ & 0.08 & 0.11 & & & & & \\
\hline \multirow[t]{3}{*}{ g.847927A > C } & CC & 0.20 & 0.16 & 0.07 & $C$ & 0.37 & 0.31 & 0.01 \\
\hline & CA & 0.33 & 0.29 & & A & 0.63 & 0.69 & \\
\hline & $\mathrm{AA}$ & 0.47 & 0.55 & & & & & \\
\hline \multirow[t]{3}{*}{ g. $846268 A>G$} & GG & 0.36 & 0.28 & 0.00 & G & 0.59 & 0.50 & 0.00 \\
\hline & GA & 0.47 & 0.44 & & A & 0.41 & 0.50 & \\
\hline & $A A$ & 0.17 & 0.28 & & & & & \\
\hline \multirow[t]{3}{*}{ g. $847219 G>C$} & GG & 0.74 & 0.86 & 0.00 & G & 0.85 & 0.93 & 0.00 \\
\hline & CG & 0.22 & 0.13 & & C & 0.15 & 0.07 & \\
\hline & $\mathrm{CC}$ & 0.03 & 0.00 & & & & & \\
\hline \multirow[t]{3}{*}{ g. $847810 C>G$} & $\mathrm{CC}$ & 0.71 & 0.73 & 0.21 & C & 0.85 & 0.85 & 0.98 \\
\hline & GC & 0.28 & 0.25 & & G & 0.15 & 0.15 & \\
\hline & GG & 0.01 & 0.03 & & & & & \\
\hline \multirow[t]{3}{*}{ g. $848253 C>A$} & $\mathrm{CC}$ & 0.84 & 0.88 & 0.16 & $C$ & 0.91 & 0.94 & 0.07 \\
\hline & $C A$ & 0.15 & 0.12 & & A & 0.09 & 0.06 & \\
\hline & AA & 0.01 & 0.00 & & & & & \\
\hline
\end{tabular}

$P$ values $<0.01$ are considered statistically significant

were significantly different between monotocous and polytocous sheep populations $(P<0.01)$.

We analyzed the polymorphism distributions of Juno gene in six sheep breeds (Table 2). The polymorphic information contents (PIC) of loci g.847219G $>\mathrm{C}$ and g.848253C $>$ A were low in each of the six sheep breeds $(P I C<0.25)$, whereas the $P I C$ in loci g.844598A $>\mathrm{G}$, g.847830T $>\mathrm{C}, \quad$ g.847927A $>\mathrm{C}, \quad$ g.846268A $>\mathrm{G}$ and g.847810C $>\mathrm{G}$ were both low $(P I C<0.25)$ and moderate $(0.25<P I C<0.5)$. Among seven polymorphic loci, only g. $847810 \mathrm{C}>\mathrm{G}$ was under Hardy-Weinberg equilibrium in all six sheep breeds (Table 2).

Association analysis between each of the seven polymorphic loci and litter size of Small Tail Han sheep revealed a significant association between locus g.848253C $>\mathrm{A}$ and litter size in different parities $(P<$ 0.05 ) (Table 3). Overall, the litter size with the CC genotype was greater than that with AA genotype at different parities, but there was no significant difference on allele frequencies between the CC and CA genotypes. Small Tail Han sheep is a polytocous breed with an average litter size of 2.67. Taking the third parity of Small Tail
Han sheep as an example, the average litter size of the CC genotype was $2.88( \pm 0.10)$, while that of the AA genotype was $1.50( \pm 0.33)$.

\section{cDNA cloning and expression profiles of Juno and Izumo1 genes in sheep \\ CDS cloning of Juno and Izumo 1}

The RT-PCR products of the Juno and Izumo1 genes from Small Tail Han sheep were 463 bp and 895 bp (Fig. S2), respectively. The Juno gene from Small Tail Han sheep was 98\% identity to the gene from goat (Capra hircus, GenBank accession: XM_018058935.1) and 95\% identity to the gene from Texel sheep (Ovis aries, GenBank accession: XM_015100756.1). The Izumo1 gene from Small Tail Han sheep was 95\% identity to the gene from goat (Capra hircus, GenBank accession: NM 001287235.1 ) and 99\% identity to the gene from Texel sheep (Ovis aries, GenBank accession: NM_ 001164492.1). The high similarity of Small Tail Han sheep Izumo1 and Juno gene sequences indicated that those genes are very conservative among Bovidae. 
Table 2 The genetic polymorphism information of seven SNPs at Juno gene in six sheep breeds

\begin{tabular}{|c|c|c|c|c|c|c|c|c|c|c|}
\hline \multirow{2}{*}{$\frac{\text { Allele }}{\text { g.844598A > G }}$} & \multirow[t]{2}{*}{ Breeds } & \multicolumn{3}{|c|}{ Genotype frequency } & \multicolumn{2}{|c|}{ Allele frequency } & \multirow[t]{2}{*}{ PIC } & \multirow[t]{2}{*}{$\mathrm{HE}$} & \multirow[t]{2}{*}{$\mathrm{NE}$} & \multirow[t]{2}{*}{ Chi-square test ( $P$-value) } \\
\hline & & GG & $\mathrm{GA}$ & AA & G & A & & & & \\
\hline & Small Tail Han sheep & 0.31 & 0.48 & 0.21 & 0.55 & 0.45 & 0.37 & 0.50 & 1.98 & 0.49 \\
\hline & Tan sheep & 0.23 & 0.53 & 0.24 & 0.49 & 0.51 & 0.37 & 0.50 & 2.00 & 0.57 \\
\hline & Sunite sheep & 0.24 & 0.47 & 0.29 & 0.47 & 0.53 & 0.37 & 0.50 & 1.99 & 0.63 \\
\hline & Suffolk sheep & 0.08 & 0.15 & 0.77 & 0.15 & 0.85 & 0.23 & 0.26 & 1.35 & 0.01 \\
\hline & Dorper sheep & 0.07 & 0.45 & 0.48 & 0.29 & 0.71 & 0.33 & 0.41 & 1.71 & 0.66 \\
\hline & Prairie Tibetan sheep & 0.33 & 0.33 & 0.33 & 0.50 & 0.50 & 0.38 & 0.50 & 2.00 & 0.05 \\
\hline \multirow[t]{7}{*}{ g.847830T > C } & & $\mathrm{CC}$ & CT & $\pi$ & C & $\mathrm{T}$ & & & & \\
\hline & Small Tail Han sheep & 0.53 & 0.39 & 0.08 & 0.72 & 0.28 & 0.32 & 0.40 & 1.67 & 0.55 \\
\hline & Tan sheep & 0.55 & 0.38 & 0.07 & 0.74 & 0.26 & 0.31 & 0.38 & 1.62 & 0.94 \\
\hline & Sunite sheep & 0.48 & 0.34 & 0.18 & 0.65 & 0.35 & 0.35 & 0.46 & 1.84 & 0.01 \\
\hline & Suffolk sheep & 0.92 & 0.08 & 0.00 & 0.96 & 0.04 & 0.07 & 0.08 & 1.08 & 0.80 \\
\hline & Dorper sheep & 0.97 & 0.03 & 0.00 & 0.98 & 0.02 & 0.03 & 0.03 & 1.03 & 0.93 \\
\hline & Prairie Tibetan sheep & 0.48 & 0.27 & 0.24 & 0.62 & 0.38 & 0.36 & 0.47 & 1.89 & 0.02 \\
\hline \multirow[t]{7}{*}{ g.847927A > C } & & $\mathrm{AA}$ & CA & CC & A & G & & & & \\
\hline & Small Tail Han sheep & 0.47 & 0.33 & 0.20 & 0.63 & 0.37 & 0.36 & 0.46 & 1.87 & 0.00 \\
\hline & Tan sheep & 0.52 & 0.29 & 0.19 & 0.66 & 0.34 & 0.35 & 0.45 & 1.80 & 0.00 \\
\hline & Sunite sheep & 0.42 & 0.35 & 0.23 & 0.60 & 0.41 & 0.37 & 0.48 & 1.93 & 0.01 \\
\hline & Suffolk sheep & 0.87 & 0.13 & 0.00 & 0.94 & 0.06 & 0.11 & 0.12 & 1.14 & 0.67 \\
\hline & Dorper sheep & 0.97 & 0.03 & 0.00 & 0.98 & 0.02 & 0.03 & 0.03 & 1.03 & 0.93 \\
\hline & Prairie Tibetan sheep & 0.43 & 0.26 & 0.31 & 0.56 & 0.44 & 0.37 & 0.49 & 1.97 & 0.00 \\
\hline \multirow[t]{7}{*}{ g. $846268 A>G$} & & AA & GA & GG & A & G & & & & \\
\hline & Small Tail Han sheep & 0.17 & 0.47 & 0.36 & 0.41 & 0.59 & 0.37 & 0.48 & 1.93 & 0.59 \\
\hline & Tan sheep & 0.11 & 0.51 & 0.38 & 0.37 & 0.63 & 0.36 & 0.47 & 1.87 & 0.37 \\
\hline & Sunite sheep & 0.21 & 0.48 & 0.30 & 0.45 & 0.55 & 0.37 & 0.50 & 1.98 & 0.83 \\
\hline & Suffolk sheep & 0.77 & 0.13 & 0.10 & 0.83 & 0.17 & 0.24 & 0.28 & 1.38 & 0.00 \\
\hline & Dorper sheep & 0.40 & 0.50 & 0.10 & 0.65 & 0.35 & 0.35 & 0.46 & 1.83 & 0.59 \\
\hline & Prairie Tibetan sheep & 0.28 & 0.44 & 0.28 & 0.50 & 0.50 & 0.38 & 0.50 & 2.00 & 0.50 \\
\hline \multirow[t]{7}{*}{ g. $847219 G>C$} & & GG & $C G$ & $\mathrm{CC}$ & G & C & & & & \\
\hline & Small Tail Han sheep & 0.74 & 0.22 & 0.03 & 0.85 & 0.15 & 0.22 & 0.25 & 1.33 & 0.05 \\
\hline & Tan sheep & 0.01 & 0.26 & 0.73 & 0.14 & 0.86 & 0.22 & 0.25 & 1.33 & 0.55 \\
\hline & Sunite sheep & 0.00 & 0.11 & 0.89 & 0.06 & 0.94 & 0.10 & 0.10 & 1.12 & 0.56 \\
\hline & Suffolk sheep & 0.00 & 0.03 & 0.97 & 0.01 & 0.99 & 0.03 & 0.03 & 1.03 & 0.93 \\
\hline & Dorper sheep & 0.00 & 0.13 & 0.87 & 0.07 & 0.93 & 0.12 & 0.12 & 1.14 & 0.70 \\
\hline & Prairie Tibetan sheep & 0.00 & 0.11 & 0.89 & 0.06 & 0.94 & 0.10 & 0.10 & 1.12 & 0.72 \\
\hline \multirow[t]{7}{*}{ g. $847810 C>G$} & & $\mathrm{CC}$ & GC & GG & C & G & & & & \\
\hline & Small Tail Han sheep & 0.71 & 0.28 & 0.01 & 0.85 & 0.15 & 0.22 & 0.26 & 1.34 & 0.08 \\
\hline & Tan sheep & 0.64 & 0.30 & 0.06 & 0.79 & 0.21 & 0.28 & 0.33 & 1.50 & 0.35 \\
\hline & Sunite sheep & 0.75 & 0.25 & 0.00 & 0.88 & 0.13 & 0.19 & 0.22 & 1.28 & 0.15 \\
\hline & Suffolk sheep & 0.85 & 0.13 & 0.03 & 0.91 & 0.09 & 0.15 & 0.16 & 1.20 & 0.18 \\
\hline & Dorper sheep & 0.53 & 0.40 & 0.07 & 0.73 & 0.27 & 0.31 & 0.39 & 1.64 & 0.90 \\
\hline & Prairie Tibetan sheep & 0.78 & 0.22 & 0.00 & 0.89 & 0.11 & 0.18 & 0.20 & 1.25 & 0.45 \\
\hline \multirow[t]{2}{*}{ g. $848253 C>A$} & & AA & CA & CC & A & C & & & & \\
\hline & Small Tail Han sheep & 0.01 & 0.15 & 0.84 & 0.09 & 0.91 & 0.14 & 0.16 & 1.18 & 0.38 \\
\hline
\end{tabular}


Table 2 The genetic polymorphism information of seven SNPs at Juno gene in six sheep breeds (Continued)

\begin{tabular}{lllllllllll}
\hline Allele & Breeds & \multicolumn{4}{l}{ Genotype frequency } & Allele frequency & PIC & HE & NE & Chi-square test $(\boldsymbol{P}$-value $)$ \\
\hline & Tan sheep & 0.01 & 0.25 & 0.74 & 0.14 & 0.86 & 0.21 & 0.24 & 1.31 & 0.63 \\
Sunite sheep & 0.00 & 0.10 & 0.90 & 0.05 & 0.95 & 0.09 & 0.10 & 1.11 & 0.60 \\
& Suffolk sheep & 0.00 & 0.00 & 1.00 & 0.00 & 1.00 & 0.00 & 0.00 & 1.00 & NA \\
Dorper sheep & 0.00 & 0.00 & 1.00 & 0.00 & 1.00 & 0.00 & 0.00 & 1.00 & NA \\
& Prairie Tibetan sheep & 0.00 & 0.11 & 0.89 & 0.06 & 0.94 & 0.10 & 0.10 & 1.12 & 0.72 \\
\end{tabular}

$P>0.05$ indicates the locus was under Hardy-Weinberg equilibrium. $P<0.05$ indicates the locus was not under Hardy-Weinberg equilibrium

\section{Full-length amplification of Juno and Izumo 1 CDNA}

Using the obtained partial RT-PCR product of the Juno gene of Small Tail Han sheep as template, a 572-bp fragment was obtained by 3' RACE, and 658 bp and 518 bp fragments were obtained by 5 ' RACE (Fig. S2). The full sequence of the Juno gene was 1131 bpwhich contained a 50-bp 5' UTR, a 349-bp 3' UTR and a 732-bp CDS. The gene contained 4 exons and 3 introns, encoding a protein comprised of 243 amino acids.

Using the partial RT-PCR product of the Izumo1 gene of Small Tail Han sheep as the template, $290 \mathrm{bp}$, and 1010 bp were obtained by 3' RACE and 5' RACE, respectively (Fig. S2). The Izumo1 gene was $1565 \mathrm{bp}$, consisting of 9 exons and 8 introns. It contained a 433-bp 5' UTR, a 97-bp 3' UTR and a 1035-bp CDS. The initial codon ATG began at nt 434 and the termination codon TAG began at nt 1466, encoding a protein 344 amino acids in length.

We previous reported that the DNA sequence of Izumo1 gene from Texel sheep (Oar_v4.0: NC_019471.2 and Oar_v3.1: NC_019471.1) was 57 shorter than the corresponding genes in Small Tail Han sheep [17]. A 35bp sequence 5'-ATGAGGCCACACTGGAAAAGGCAT CCTGGAGTTTG-3' derived from this $57 \mathrm{bp}$ DNA sequence. The 35 bp insertionfrom 239-273 bp of the CDS sequence of the Izumo1 gene in Small Tail Han sheep did not exist in the CDS of Texel sheep (Fig. 1).

After sequence alignment, it demonstrated that $35 \mathrm{bp}$ of the extra $57 \mathrm{bp}$ belongs to exon 2 (Fig. 1c, Exon 2 in Small Tail Han sheep Part 1), while the other $22 \mathrm{bp}$

Table 3 Association of different SNP genotypes of the Juno gene with litter size in Small Tail Han sheep

\begin{tabular}{|c|c|c|c|c|c|c|c|}
\hline Locus & Genotype & $\begin{array}{l}\text { No. of the } \\
1 \text { st parity }\end{array}$ & $\begin{array}{l}\text { Litter size of the } \\
\text { 1st parity }\end{array}$ & $\begin{array}{l}\text { No. of the } \\
\text { 2nd parity }\end{array}$ & $\begin{array}{l}\text { Litter size of the } \\
\text { 2nd parity }\end{array}$ & $\begin{array}{l}\text { No. of the } \\
\text { 3rd parity }\end{array}$ & $\begin{array}{l}\text { Litter size of the } \\
\text { 3rd parity }\end{array}$ \\
\hline \multirow[t]{3}{*}{ g. $844598 \mathrm{~A}>\mathrm{G}$} & AA & 74 & $2.15 \pm 0.09$ & 78 & $2.32 \pm 0.10$ & 21 & $3.00 \pm 0.22$ \\
\hline & GA & 159 & $2.06 \pm 0.06$ & 175 & $2.24 \pm 0.06$ & 69 & $2.77 \pm 0.12$ \\
\hline & GG & 102 & $2.26 \pm 0.08$ & 114 & $2.19 \pm 0.08$ & 36 & $2.98 \pm 0.17$ \\
\hline \multirow[t]{3}{*}{ g.847830T > C } & CC & 175 & $2.19 \pm 0.06$ & 191 & $2.21 \pm 0.06$ & 21 & $2.87 \pm 0.12$ \\
\hline & $\mathrm{CT}$ & 131 & $2.07 \pm 0.07$ & 142 & $2.35 \pm 0.07$ & 36 & $2.93 \pm 0.14$ \\
\hline & $\pi$ & 28 & $2.10 \pm 0.15$ & 31 & $2.32 \pm 0.15$ & 69 & $2.57 \pm 0.39$ \\
\hline \multirow[t]{3}{*}{ g. $847927 A>C$} & AA & 158 & $2.18 \pm 0.06$ & 171 & $2.23 \pm 0.07$ & 62 & $2.94 \pm 0.13$ \\
\hline & CA & 110 & $2.10 \pm 0.07$ & 76 & $2.28 \pm 0.10$ & 16 & $2.56 \pm 0.25$ \\
\hline & $\mathrm{CC}$ & 67 & $2.11 \pm 0.10$ & 119 & $2.32 \pm 0.08$ & 49 & $2.94 \pm 0.15$ \\
\hline \multirow[t]{3}{*}{ g.846268A > G } & AA & 57 & $2.15 \pm 0.10$ & 64 & $2.23 \pm 0.11$ & 25 & $3.00 \pm 0.20$ \\
\hline & GA & 159 & $2.17 \pm 0.06$ & 174 & $2.25 \pm 0.07$ & 66 & $2.89 \pm 0.13$ \\
\hline & GG & 123 & $2.11 \pm 0.07$ & 133 & $2.29 \pm 0.08$ & 39 & $2.74 \pm 0.16$ \\
\hline \multirow[t]{3}{*}{ g. $847219 G>C$} & CC & 12 & $2.33 \pm 0.23$ & 13 & $2.00 \pm 0.24$ & 3 & $2.33 \pm 0.59$ \\
\hline & $C G$ & 74 & $2.14 \pm 0.09$ & 83 & $2.21 \pm 0.09$ & 25 & $2.70 \pm 0.20$ \\
\hline & GG & 255 & $2.12 \pm 0.05$ & 277 & $2.29 \pm 0.05$ & 102 & $2.92 \pm 0.10$ \\
\hline \multirow[t]{3}{*}{ g. $847810 C>G$} & CC & 231 & $2.14 \pm 0.05$ & 260 & $2.22 \pm 0.05^{a}$ & 87 & $2.85 \pm 011$ \\
\hline & GC & 98 & $2.15 \pm 0.08$ & 100 & $2.39 \pm 0.09^{\mathrm{a}}$ & 36 & $2.97 \pm 0.17$ \\
\hline & GG & 4 & $2.25 \pm 0.39$ & 4 & $1.50 \pm 0.43^{b}$ & 2 & $2.50 \pm 0.73$ \\
\hline \multirow[t]{3}{*}{ g. $848253 C>A$} & AA & 4 & $1.25 \pm 0.39^{a}$ & 4 & $1.25 \pm 0.43^{a}$ & 4 & $1.50 \pm 0.33^{\mathrm{a}}$ \\
\hline & CA & 48 & $2.13 \pm 0.11^{b}$ & 54 & $2.17 \pm 0.12^{b}$ & 10 & $2.91 \pm 0.31^{b}$ \\
\hline & $C C$ & 281 & $2.13 \pm 0.05^{b}$ & 307 & $2.28 \pm 0.05^{b}$ & 116 & $2.88 \pm 0.10^{b}$ \\
\hline
\end{tabular}

\footnotetext{
${ }^{\mathrm{a}, \mathrm{b}}$ : Different lowcases indicate statistically significant differences $(P<0.05)$
} 


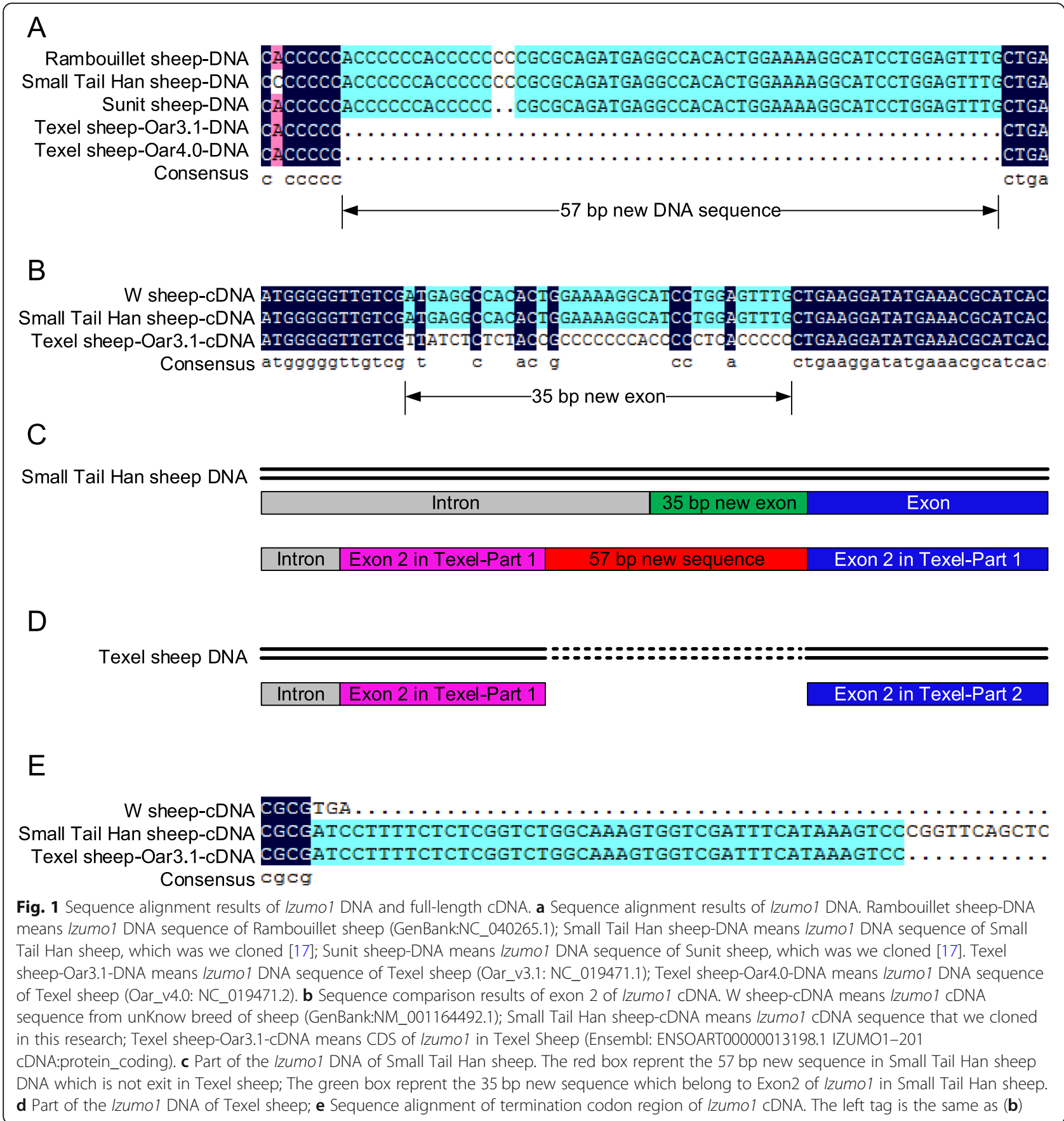

belongs to intron 1 (Fig. 1c) in Small Tail Han sheep. We further compared the CDS of Izumo1 in Texel Sheep (Ensembl: ENSOART00000013198.1 IZUMO1-201 cDNA:protein_coding) and found that the second half of exon 2 (exon 2 in Texel sheep-Part 2) was the same as that of Small Tail Han sheep (exon 2 in Small Tail Han sheep-Part 2). But the first half sequence of exon 2 of Texel Sheep (exon 2 in Texel sheep-Part 1) was in the intron 1 region of the Izumo1 genome of Small Tail Han sheep (Fig. 1b, c, d). We speculated that the 57 bp DNA sequence of Small Tail Han sheep may lead to different transcript splicing patterns. In addition, we compared the Izumo1 DNA sequence of Rambouillet sheep to that from Small Tail Han sheep (Fig. 1a, GenBank accession: NC_040265.1). The Izumo1 DNA sequence of Rambouillet sheep was highly similar to that of Small Tail Han sheep and Sunite sheep and it contained a similar insert. We suspect the CDS of Rambouillet sheep may also be similar to that of Small Tail Han sheep and Sunite sheep. 
In addition, we found that there were only eight exons in the sheep Izumo1 CDS in the NCBI database (GenBank accession: NM_001164492.1), and the CDS region of the sequence terminated early at exon 8. The full-length Izumo1 cDNA sequence of Small Tail Han sheep we obtained had nine complete exons (Fig. 1e). The cDNA sequence of Izumo1 of Texel Sheep provided in the Ensembl database (Ensembl: ENSOART00000013198.1 IZUMO1-201 cDNA: protein_coding) was incomplete, and the position of the terminator was not indicated. Therefore, this study provides the first full-length Izumo1 cDNA sequence of sheep.

\section{Differential expression analysis of Juno and Izumo1 genes in tissues of sheep}

Semi-quantitative RT-PCR results showed that the Juno gene was expressed in ovaries and oviducts both in Small Tail Han sheep and Sunite sheep, but not in the other 14 tissues tested (Fig. 2a). The Izumo1 gene was expressed only in the testes and epididymis of Small Tail Han sheep and Sunite sheep, but not in the other 14 tissues tested. The expression level of Izumo1 in the testes of the two sheep breeds was higher than that in the epididymis (Fig. 2b).

The expression of Juno and Izumo1 in different tissues of the reproductive gonad axis of sheep was measured by RT-qPCR (Fig. 3). Juno expression was significantly higher in the ovaries than all other tissues $(P<0.01)$, but there was no significant difference between Small Tail Han sheep and Sunite sheep $(P>0.05)$. Expression of Izumo1 was higher in the testes than all other tissues $(P<0.01)$, but there was no difference between expression in the other tissues. Unlike Juno, the expression of Izumo1 in the testes of Small Tail Han sheep, a polytocous breed, was significantly higher than that in Sunite sheep, a monotocous breed $(P<0.01)$. Although the expression of Izumo1 in other tissues of Small Tail Han sheep was higher than that of Sunite sheep, the difference was not significant $(P>0.05)$.

\section{Gene expression profiles at single cell levels}

There are many types of cells in ovarian tissue, and there is heterogeneity between cells. To further explore the expression and function of the Juno gene in different types of cells in ovarian tissue, we collected single cells, including oocytes, granulosa cells and follicular theca of polytocous and monotocous Small Tail Han ewes, and sequenced them by single cell RNA-seq. The expression levels of Juno, BMP15 and GDF9 were very high in oocytes, but very low in granulosa cells and follicular theca (Fig. 4). However, expression of BMPR1B and CD9 was high in granulosa cells and follicular theca but very low in oocytes. At the same time, we found that Izumo1 had barely expression in all three cell types. The results showed that in ovarian tissue, Juno was specifically expressed in oocytes, while Izumo1 was specifically expressed in testes, consistent with the function of the two genes. In addition, there was no difference in the expression of Juno in oocytes or ovaries between polytocous and monotocous Small Tail Han sheep, suggesting the difference in litter size is not caused by the level of Juno expression, but is possibly due to some other factor.

\section{Bioinformatic analysis of JUNO and IZUMO1 proteins Physicochemical properties of JUNO and IZUMO1 proteins} ProtParam revealed that molecular weights of JUNO and IZUMO1 proteins are $27.93 \mathrm{kDa}$ and $38.89 \mathrm{kDa}$, respectively. As shown in Figure S3, the signal peptide region at the N-terminus of JUNO and the anchoring region at the $\mathrm{C}$-terminus had strong hydrophobic regions, among which leucine at position 235 was the most hydrophobic (the highest score is 2.5); in the mature peptide region, hydrophobic amino acids and hydrophilic amino acids were evenly distributed. The signal peptide region at the $\mathrm{N}$-terminus and the transmembrane region at the $\mathrm{C}$ terminus of IZUMO1 had strong hydrophobic regions, of which the IIe at position 319 had the strongest hydrophobicity (the highest score was 3.567 ); hydrophobic and hydrophilic amino acids were also evenly distributed in the mature peptide region.

\section{Advanced structural prediction of JUNO and IZUMO1 in Small Tail Han sheep}

The secondary structures of Small Tail Han sheep JUNO and IZUMO1 proteins were predicted (Fig. 5). Mutation of the Juno gene at the g.848253C > A locus caused an amino acid change from Phe to Leu at position 219. The predicted secondary structures showed there were 14 protein binding regions in the JUNO protein before the mutation at g.848253C $>\mathrm{A}$. After the mutation, three protein binding regions $(143,171$, and 228) were lost. There were only five protein binding regions in the predicted secondary structure of IZUMO1, based on the full-length IzumoI cDNA of Small Tail Han sheep. But there were two disulfide bonds in the IZUMO1 protein.

Phyre2 was used to analyze the tertiary structures of JUNO and IZUMO1 from Small Tail Han sheep (Fig. 6). The tertiary structure of JUNO was clustered with human oocyte surface protein JUNO, having $75 \%$ similarity, whereas it had only $62 \%$ similarity to folate receptor $\alpha$. The tertiary structure of Small Tail Han sheep IZUMO1 was rod-shaped, and had $74 \%$ similarity with human sperm IZUMO1.

\section{Sequence alignment and phylogenetic analysis of JUNO and IZUMO1 proteins}

The homology between JUNO and IZUMO1 protein orthologs was analyzed. The results showed that the amino 


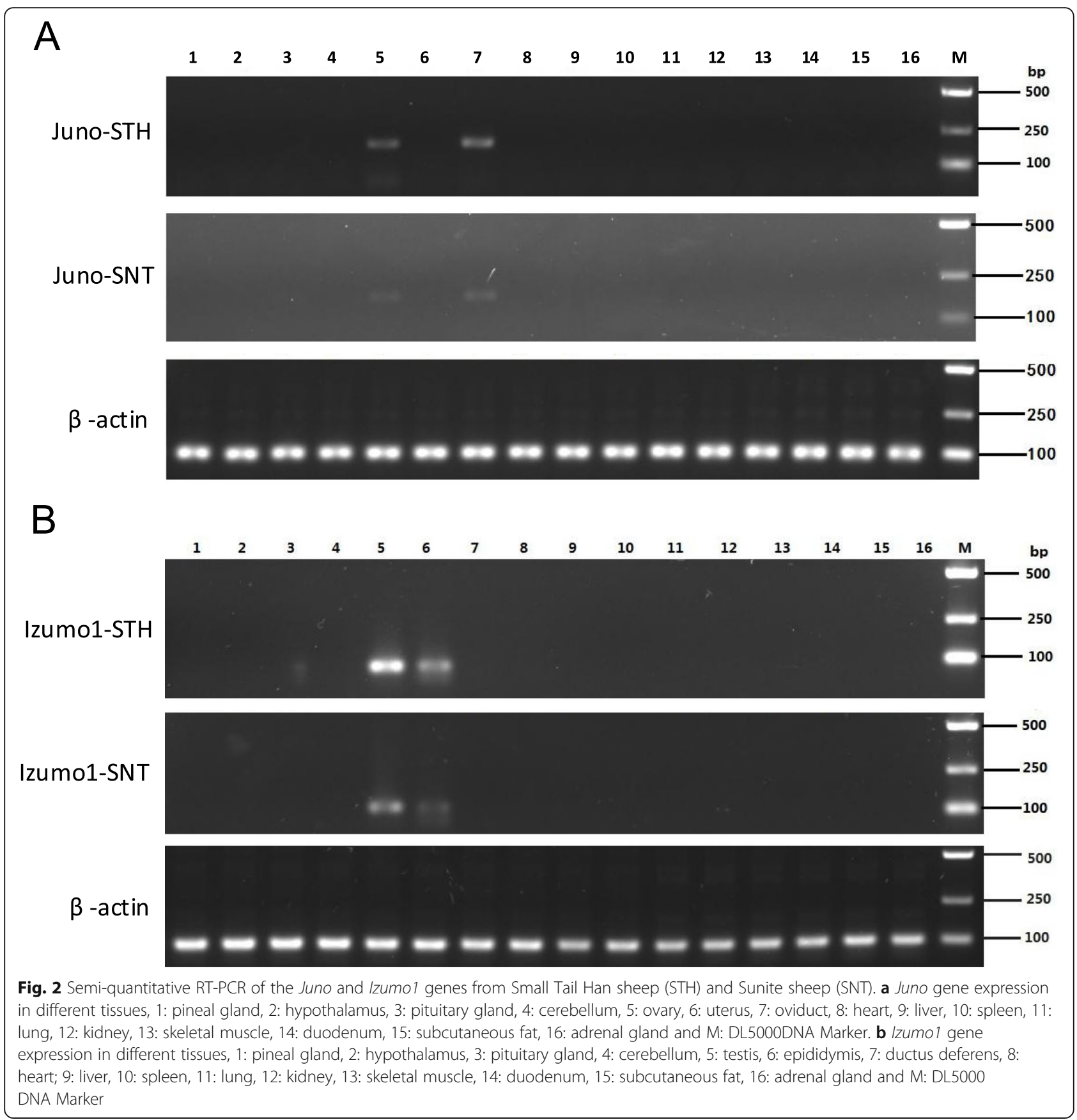

acid sequence of JUNO and IZUMO1 in Small Tail Han sheep were conservative among sheep, goat and wild yak. The similarity was much lower with wild boar, human, rhesus monkey, rabbit, rat and mouse (Table 4). A phylogenetic tree was constructed for JUNO and IZUMO1 using the Neighbor-Joining method (Fig. 7). Small Tail Han sheep and sheep (Ovis aries) first gathered into one branch, then gathered together with goat (Capra hircus).

We also compared the amino acid sequences of JUNO proteins from different species. We found that compared with human and mouse JUNO proteins, the mutated amino acid (F219L) in Small Tail Han sheep was located in $\alpha 5$ region of human JUNO protein [12] and $\alpha 7$ region of mouse JUNO protein [18], which was closed to GPI signal region, but not belong to residues that interact with Izumo1 and the other three flexible regions.

\section{Discussion}

The cloning of Juno and Izumo 1 genes

Research on the Juno gene has mainly focused on its role in mouse and human tumors [19-21], whereas research 


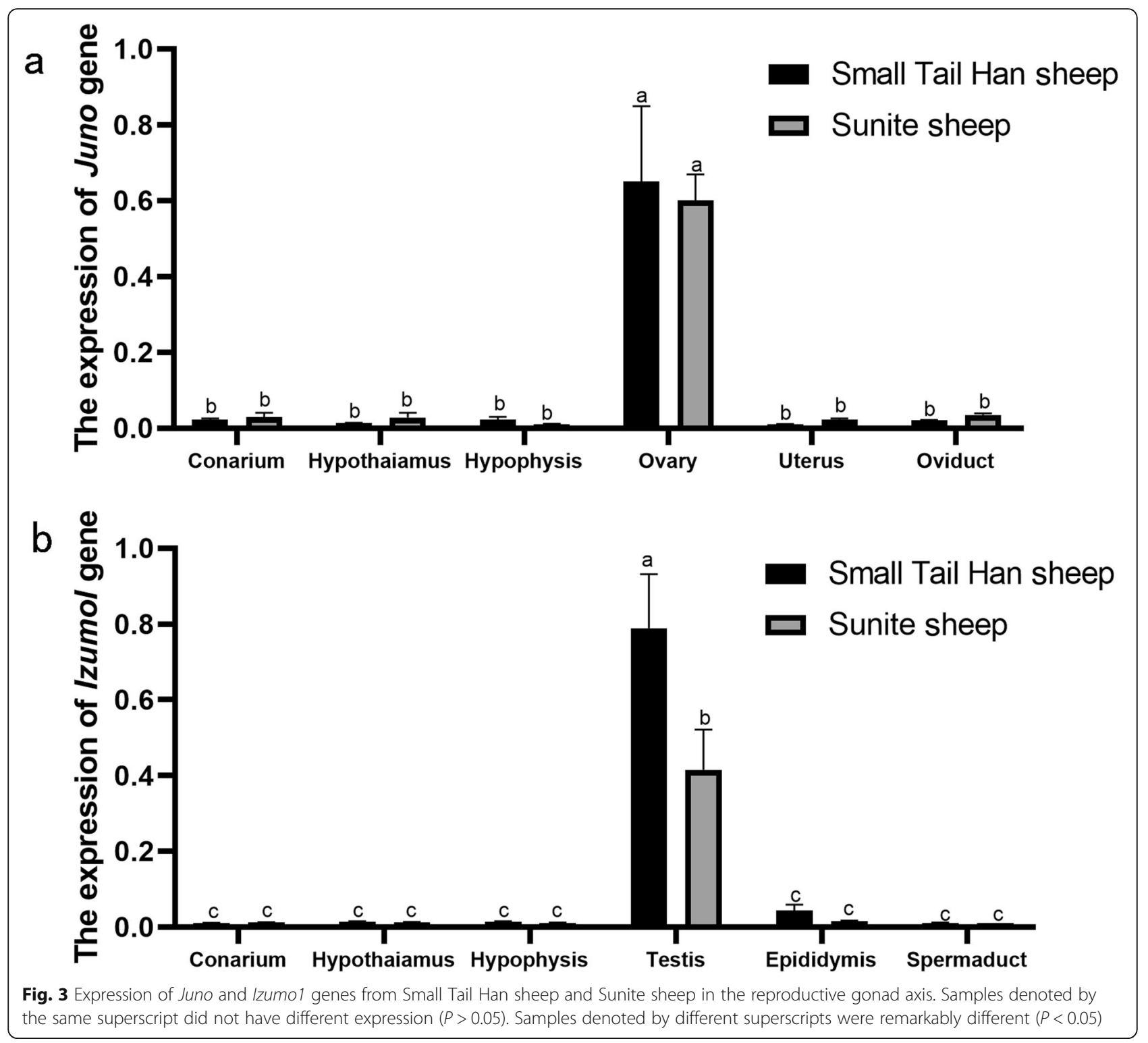

on its roles in reproduction is relatively rare. At present, there is no complete report of the Juno gene sequence in sheep, and there is no full-length cDNA sequence of the Juno gene in Small Tail Han sheep, a polytocous sheep breed famous in China. In this study, the complete DNA and cDNA sequences of the Small Tail Han sheep Juno gene were successfully obtained. The phylogenetic tree showed that the Small Tail Han sheep JUNO protein had the closest relationship with goat and sheep; the similarity was over $96 \%$, indicating the JUNO protein has been highly conserved throughout evolution.

After identification of the IZUMO1 protein by Inoue et al. [1], many studies have been done on the mammalian Izumo1 gene, but the cloning and analysis of its cDNA sequence have mostly focused on human and mouse, with a couple of exceptions. Xing et al. [14] cloned and obtained the cDNA sequence of the Izumo1 gene of the cashmere goat and sheep (breed unknown). Evaluation of the sequences revealed a typical ORF of $963 \mathrm{bp}$ that could be spliced into 8 exons. Kim et al. [13] cloned and obtained the complete ORF sequence of the porcine Izumo1 gene using RACE technology. We found that most of the currently published Izumo1 cDNA sequences contained a 963-bp ORF, encoding a 320 -amino acid protein, which is consistent with the results of this study, showing that the amino acid sequence of IZUMO1 is relatively conserved among species. Although the Izumo1 cDNA sequence has been reported in sheep, the breed is unknown and there is no full-length cDNA sequence for Small Tail Han sheep. Previously, we were the first to clone the full-length Izumo1 DNA sequence of Small Tail Han sheep [17], and in this study, we obtained the first full-length Izumo1 


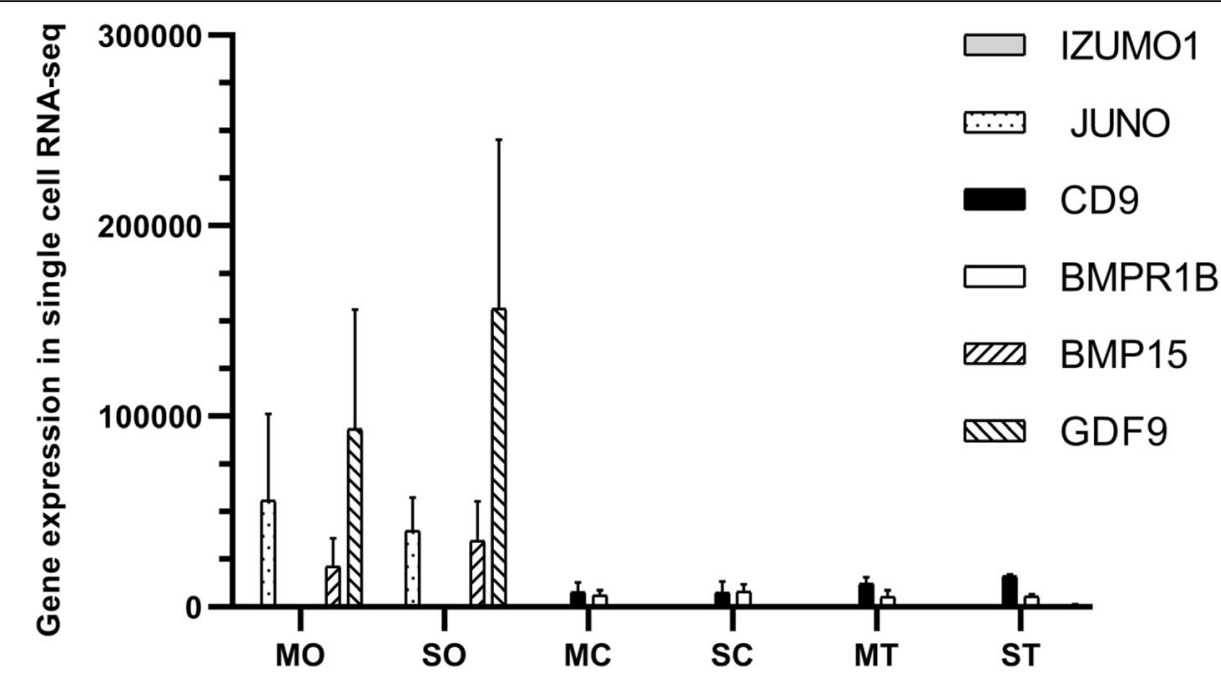

Fig. 4 Expression of genes by single cell RNA-seq. MO: oocyte of polytocous sheep, SO: oocyte of monotocous sheep, MC: granulosa cell of polytocous sheep, SC: granulosa cell of monotocous sheep, MT: follicular theca of polytocous sheep and ST: follicular theca of monotocous sheep

cDNA sequence of sheep. Alignment of the Small Tail Han sheep Izumo1 CDS with the sequence from Texel sheep (the reference genome) revealed Small Tail Han sheep Izumo1 contains an additional segment of CDS that is $35 \mathrm{bp}$ in length. Furthermore, we compared the DNA and cDNA sequences of Izumo1 from all sheep and found that the Izumo1 gene has nine exons, not eight as was previously thought. This study provides the basis for future research of the Izumo1 gene.

The amino acid homology analyses showed that Small Tail Han sheep IZUMO1 had 95\% or higher similarity with sheep, goat and cattle. The phylogenetic tree showed that the IZUMO1 protein of Small Tail Han sheep was closely related to that of sheep, goat and

A

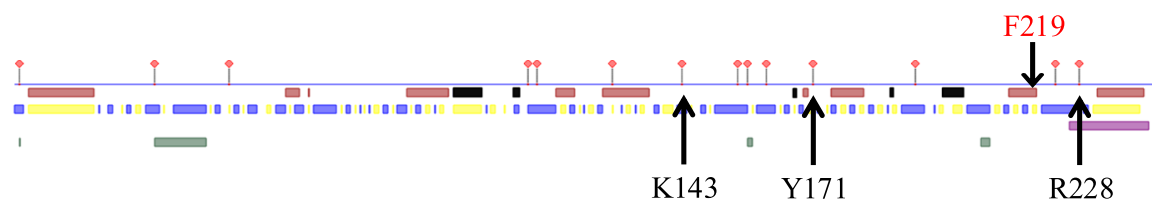

B

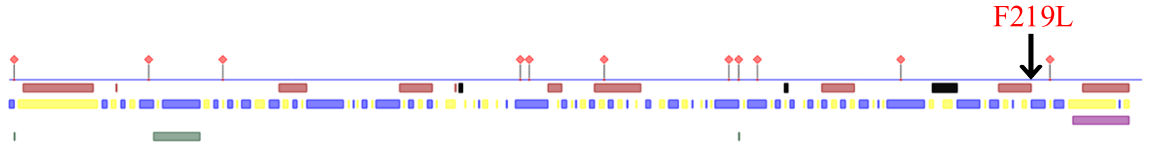

C

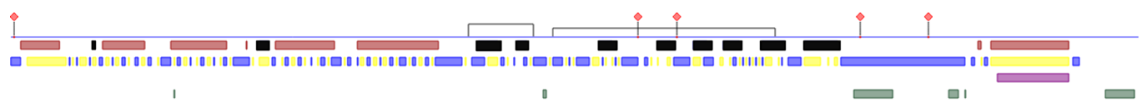

I Protein binding site

Helix

Strand

Exported

Disulfide bond

Helical transmembrane region

$\square$ Disordered region

Fig. 5 Predicted secondary structure of JUNO and IZUMO1 proteins in Small Tail Han sheep. a Predicted secondary structure of JUNO before the mutation at the g.848253C > A locus, based on the full-length Juno CDNA of Small Tail Han sheep. $\mathbf{b}$ Predicted secondary structure of JUNO after the mutation at g.848253C > A, based on the full-length Juno cDNA of Small Tail Han sheep. c Predicted secondary structure of IZUMO1, based on the full-length Izumo1 cDNA of Small Tail Han sheep 

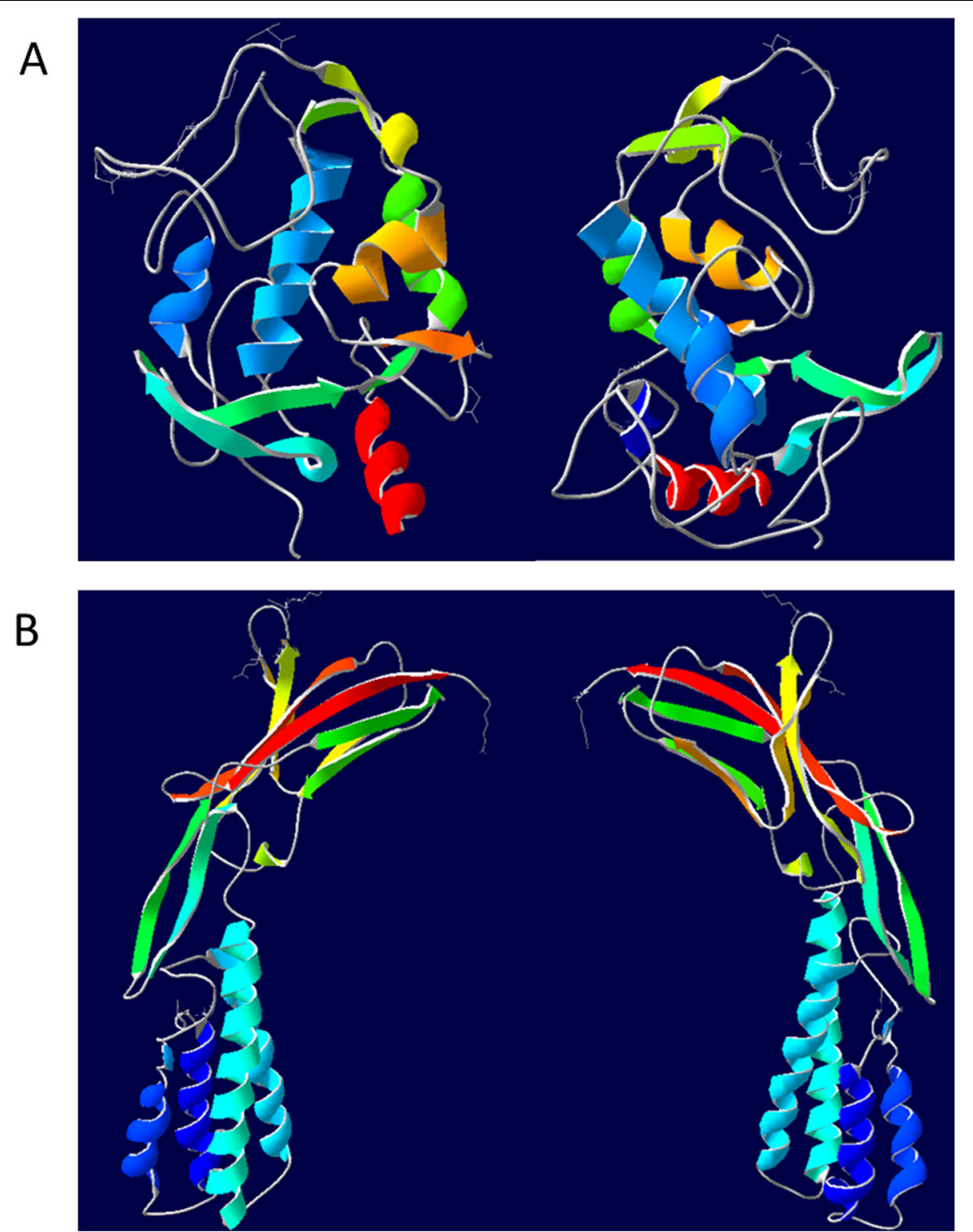

Fig. 6 Predicted 3D structures of JUNO (a) and IZUMO1 (b) from Small Tail Han sheep

cattle, indicating that the IZUMO1 protein has been relatively conserved throughout evolution in Bovidae.

\section{Expression of Juno and Izumo 1 genes}

Oocytes are produced in the ovary and mature there. They next enter the oviduct where they await fertilization by the sperm, and time is limited. Once fertilized, oocytes travel to the uterus for implantation. Therefore, the oocyte content in oviduct and uterus is relatively low and fluctuates greatly with time. Transcriptomic data of 40 different sheep tissues showed that expression of Juno in lymph node mesenteric, lymph node prescapular and peyer's patch was the highest, followed by that in ovarian follicles
[22]. Juno expression in the ovary was slightly lower than in ovarian follicles, while expression in the uterus and corpus luteum was very low [22]. The quantitative results of the present study showed that Juno mRNA was highly expressed in ovary, but weakly or not at all expressed in the oviduct, uterus and other tissues, consistent with transcriptomic data. From the RT-PCR result the Juno had a highly expressed in oviduct, but we believed it might be because of the accuracy of this assay. In order to solve this problem, qPCR and single cell RNA-seq were performed to quantify the expression of Juno precisely.

In this study, single cell RNA-seq data showed that expression of Juno was very high in oocytes, but very low 
Table 4 The homology between protein orthologs

\begin{tabular}{|c|c|c|c|c|c|}
\hline \multirow[t]{2}{*}{ Species } & & \multicolumn{2}{|l|}{ JUNO } & \multicolumn{2}{|l|}{ IZUMO1 } \\
\hline & & $\begin{array}{l}\text { Accession } \\
\text { number }\end{array}$ & $\begin{array}{l}\text { Similarity of amino acid sequence } \\
\text { with Small Tail Han sheep }\end{array}$ & $\begin{array}{l}\text { Accession } \\
\text { number }\end{array}$ & $\begin{array}{l}\text { Similarity of amino acid sequence } \\
\text { with Small Tail Han sheep }\end{array}$ \\
\hline Sheep & Ovis aries & XP_027834903.1 & $99.6 \%$ & NP_001157964.1 & $99.7 \%$ \\
\hline Goat & Capra hircus & XP_017914424.1 & $97.1 \%$ & NP_001274164.1 & $98.7 \%$ \\
\hline Wild yak & Bos mutus & XP_005907338.1 & $95.5 \%$ & XP_014333597.1 & $95.3 \%$ \\
\hline Wild boar & Sus scrofa & XP_013834737.2 & $79.8 \%$ & XP_003127333.3 & $75.6 \%$ \\
\hline Human & Homo sapiens & NP_001186135.1 & $70.4 \%$ & NP_872381.2 & $65.9 \%$ \\
\hline Monkey & Macaca mulatta & NP_001180734.1 & $69.4 \%$ & NP_001181552.1 & $65.3 \%$ \\
\hline Rabbit & Oryctolagus cuniculus & XP_017204775.1 & $71.2 \%$ & XP_017195294.1 & $54.3 \%$ \\
\hline Rat & Rattus norvegicus & XP_017451453.1 & $63.8 \%$ & NP_001017514.1 & $54.8 \%$ \\
\hline Mouse & Mus musculus & NP_075026.1 & $60.9 \%$ & NP_001018013.1 & $49.6 \%$ \\
\hline
\end{tabular}

in granulosa cells and follicle theca. Juno was specifically expressed in oocytes in ovarian tissue, which is consistent with the high expression of Juno gene in ovarian follicles in tissue transcriptomic data [22]. It can also be inferred that Juno is specifically expressed in oocytes, but not in other ovary cell types. The specific expression of Juno in oocytes is related to its function as a receptor during fertilization.
$B M P R 1 B, B M P 15$ and GDF9 are all family members of TGF- $\beta$ pathway. They are also major regulatory genes for litter size in sheep [23]. GDF9 and BMP15 produced by oocytes bind to the BMPR $1 B$ receptor located on granulosa cells and act through BMPR1B to jointly stimulate proliferation of granulosa cells [24], which is critical for normal follicular development in sheep. Whether in human or sheep, GDF9 and BMP15 have
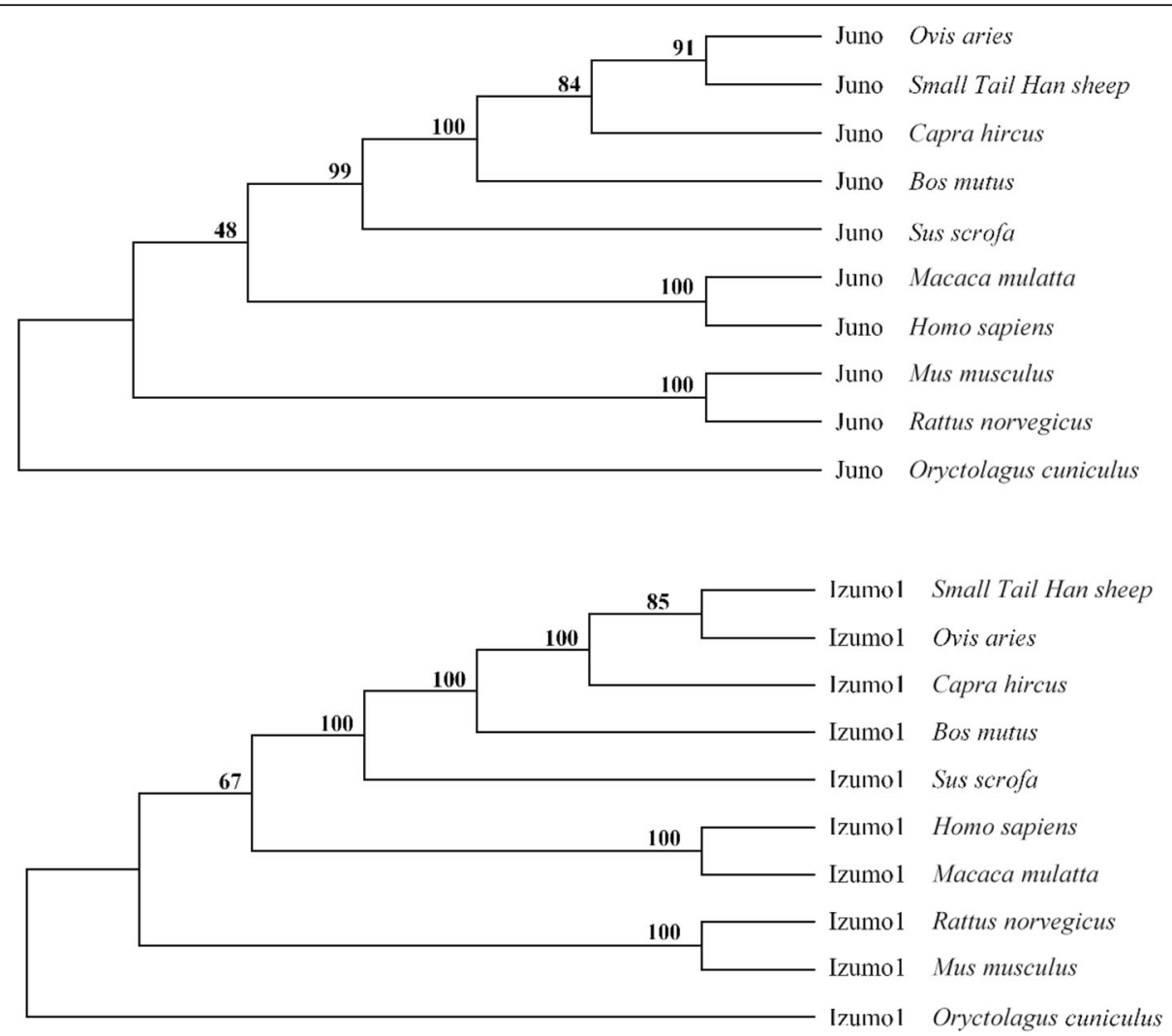

Fig. 7 Phylogenetic analysis of JUNO and IZUMO1 proteins in Small Tail Han sheep 
the same expression pattern in follicles $[25,26]$. Our single cell RNA-seq data also proved that BMP15 and GDF9 are highly expressed in oocytes, whereas BMPR1B was highly expressed in granulosa cells. Our RNA-seq data was very consistent with previous results. Like BMP15 and GDF9, Juno was specifically expressed in oocytes. However, in both single cells and tissue samples, there was no difference in the expression of Juno in sheep differing in litter size, indicating that expression of Juno is not related to litter size.

Satouh et al. has firstly described the exposure of IZUMO1 precisely. They visualized the dynamics of diffusion of IZUMO1 at the time of the acrosome reaction using a fluorescent protein tag. IZUMO1 localized in the equatorial segment of the sperm surface after the acrosome reaction [27]. Inoue et al. used a polyclonal antibody prepared by recombinant IZUMO protein for immunolabeling and found that the size of IZUMO in mice is $56.4 \mathrm{kDa}$, and that it is only expressed in the testes of mice [1]. Kim et al. also confirmed that IZUMO1 is only exposed on the sperm head during sperm-oocyte fusion [13]. Sperm is produced in the testes and then stored in the epididymis. Only when ejaculating will sperm pass through the sperm duct; thus, sperm content in sperm duct should be relatively low. Our data showed that there is a low level of expression in the epididymis, which may be due to the storage of some mature sperm in epididymis.

The structure and function of JUNO and IZUMO1 proteins JUNO and IZUMO1 proteins play an important role in the process of sperm and oocyte fusion. The JUNOIZUMO1 recognition system has been deciphered by Xray crystallography $[12,28]$. After JUNO-IZUMO1 recognition, the dimer IZUMO1 may also specifically recognize a second unknown receptor on the oocyte surface. Sperm-oocyte fusion is a multi-molecule event, and there may be many other molecules involved. Research showed that recognition and binding of JUNO and IZUMO1 is a relatively weak adhesion [29]. After the sperm enters the zona pellucida, IZUMO1 adheres to JUNO, and CD9 on the oocyte accumulates between cells before sperm and oocyte fusion. CD9 was considered to be a protein cooperating with JUNO [30]. This adhesion is conserved in both human and mouse oocytes [10]. Moreover, this kind of adhesion may be transient, needs a sensitive detection method, such as highly sensitive interaction assay [8]. It is also well established that after the first adhesion event between JUNO and IZUMO1, JUNO is released out of the oocyte membrane. Forty minutes after sperm and oocyte fusion, JUNO can longer be detected on the surface of the oocyte membrane. The shedding of JUNO protein is a gradient reaction, which is completed within $40 \mathrm{~min}$. The shedding mechanism of JUNO is closely related to the prevention of multiple sperm from entering the oocyte, ensuring the oocyte will only fuse with one sperm under natural conditions [11].

The tertiary structure prediction of JUNO showed that it has a compact structure with a pocket in the center, which may play an important role in the recognition and binding of ligands or receptor proteins [18]. The tertiary structure prediction of IZUMO1 from Small Tail Han sheep had two stable $\beta$-hairpins in the central region of the tertiary structure. Moreover, the $\alpha$-helix domain in the front end and the immunoglobulin domain in the back end are firmly bound by a disulfide bond to form a slender rod-shaped protein, similar to the tertiary structure of human IZUMO1 $[12,28]$. Ohto et al. established that the disulfide bond formed in the $\beta$-hairpin region of the IZUMO1 protein is very important to maintain its structural stability [28].

The mutation of the Juno gene at locus g.848253C > A will lead to a change from Phe to Leu at site 219 in the amino acid sequence. This single amino acid difference causes a loss of three protein binding sites in JUNO. Interestingly, there was a significant association between the g.848253C > A locus and litter size of Small Tail Han sheep: the litter size of the AA genotype was significantly smaller than the litter size of the CC and CA genotypes. In the 3rd parity, the litter size of sheep with the AA genotype decreased by nearly 1.38 offspring compared with the CC genotype, and there was no difference in litter size between $\mathrm{CC}$ and CA genotypes. The latest research showed that four SNPs of the Juno gene were found in women with fertilization failure and polyspermy, and variation of Juno may have played a role in this pathogenesis [31]. If compare with human and mouse, this mutated amino acid (F219L) in Small Tail Han sheep was not belong to motifs that interact with Izumo1. At present, we don't know the specific function of this region, but it can be seen that this amino acid is essential for the functionality of JUNO protein in sheep. More functional analysis will be performed to make our doubt clearly in our future research.

\section{Conclusions}

In this study, we successfully obtained the full-length DNA sequence of the Juno gene, screened nine SNPs of Juno and genotyped these loci. The association analysis showed a significant association between different genotypes of the g.848253C > A locus and litter size of Small Tail Han sheep. The full-length cDNA sequences of Juno and Izumo1 were obtained and $35 \mathrm{bp}$ of new Izumo1 CDS sequence of in Small Tail Han sheep was found, and we confirmed the Izumo1 gene has nine exons, not eight exons. Expression analysis showed that the Juno 
gene was highly expressed in ovary, whereas the Izumo1 gene was highly expressed in testes. In addition, expression of the Izumo1 gene in the testes of polytocous Small Tail Han sheep was significantly higher than that in monotocous Sunite sheep, indicating that expression of Izumo1 in testes positively correlates to fecundity. Single cell RNA-seq showed Juno is specifically expressed in oocytes, but not in granulosa cells and follicular theca, while Izumo 1 was barely expressed in all three cell types. There was no difference in the expression of Juno in oocyte and ovarian tissue in sheep with different litter size, indicating expression of Juno is not related to litter size traits. Bioinformatic analysis revealed the g.848253C > A locus of Juno results in a nonconservative missense point mutation leading to a change from Phe to Leu at position 219 in the amino acid sequence. For the first time, this study systematically analyzed the expression, structure and function of Juno and Izumo1 genes and their encoded proteins in Small Tail Han sheep, providing the basis for further research, unravelling the functional mechanisms of Juno and Izumo1 genes in sheep.

\section{Supplementary Information}

The online version contains supplementary material available at https://doi. org/10.1186/s40104-021-00548-4.

Additional file 1: Supplementary Materials: Fig. S1: Electrophoresis of PCR products of the Juno gene. Fig. S2: Clone and RACE results of the Juno and Izumol genes from Small Tail Han sheep. Fig. S3: Prediction of hydrophobicity in Small Tail Han sheep JUNO and IZUMO1 proteins. Table S1: Primers used for amplifying DNA of the Juno gene in sheep, Table S2: Primers used for amplifying CDNA and RT-qPCR of the Juno and Izumol genes in sheep. Table S3. SNP loci screening.

\section{Acknowledgements}

We thanks to associate professor Xiaosheng Zhang and Jinglong Zhang of Tianjin Institute of Animal Sciences for their help in sheep estrus.

\begin{abstract}
Authors' contributions
Conceptualization, W.H., M.C., and Q.L.; methodology, W.H., Z.T., Z.Z. and Q.L.; software, X.D. and Z.Z.; validation, X.D., W.H. and Z.T.; formal analysis, X.D. and W.H.; investigation, X.D.; resources, J.T. and B.L.; data curation, X.D. and W.H.; writing —original draft preparation, W.H.; writing — review and editing, W.H., M.C., and Q.L.; visualization, W.H. and X.D.; supervision, M.C., and Q.L.; project administration, W.H., M.C., and Q.L.; funding acquisition, W.H. and M.C. All authors have read and agreed to the published version of the manuscript.
\end{abstract}

\section{Funding}

This research was funded by National Natural Science Foundation of China, grant number 31501941; Central Public-interest Scientific Institution Basal Research Fund, grant number 2018-YWF-YB-1, and 2015ywf-zd-2; the Earmarked Fund for China Agriculture Research System, grant number CARS-38; the Agricultural Science and Technology Innovation Program of China, grant number ASTIP-IAS13.

\section{Availability of data and materials}

The datasets during and/or analysed during the current study available from the corresponding author on reasonable request.

\section{Ethics approval and consent to participate}

All animal used in this study were approved by the Science Research Department of the Institute of Animal Science at the Chinese Academy of Agricultural Sciences (IAS-CAAS; Beijing, China), which is in charge of animal welfare issues. In addition, there was ethics approval by the animal ethics committee of the IAS-CAAS (No. IAS2020-63).

\section{Consent for publication}

The authors declare consent for publication.

\section{Competing interests}

The authors declare no competing interests.

\section{Author details}

${ }^{1}$ Key Laboratory of Animal Genetics and Breeding and Reproduction of Ministry of Agriculture and Rural Affairs, Institute of Animal Sciences, Chinese Academy of Agricultural Sciences, Beijing 100193, China. ${ }^{2}$ Institute of Animal Husbandry and Veterinary Medicine, Anhui Academy of Agricultural Sciences, Hefei 230031, China. ${ }^{3}$ Institute of Genetics and Developmental Biology, the Innovation Academy for Seed Design, Chinese Academy of Sciences, Beijing 100101, China.

Received: 12 June 2020 Accepted: 5 January 2021

Published online: 12 March 2021

\section{References}

1. Inoue N, Ikawa M, Isotani A, Okabe M. The immunoglobulin superfamily protein Izumo is required for sperm to fuse with eggs. Nature. 2005; 434(7030):234-8.

2. Grayson P, Civetta A. Positive selection and the evolution of Izumo genes in mammals. Int J Evol Biol. 2012;2012:958164.

3. Ikawa M, Inoue N, Benham AM, Okabe M. Fertilization: a sperm's journey to and interaction with the oocyte. J Clin Invest. 2010;120(4):984-94.

4. Le Naour F, Rubinstein E, Jasmin C, Prenant M, Boucheix C. Severely reduced female fertility in CD9-deficient mice. Science. 2000;287(5451):31921.

5. Miyado K, Yamada G, Yamada S, Hasuwa H, Nakamura Y, Ryu F, et al. Requirement of CD9 on the egg plasma membrane for fertilization. Science. 2000;287(5451):321-4.

6. Kaji K, Oda S, Shikano T, Ohnuki T, Uematsu Y, Sakagami J, et al. The gamete fusion process is defective in eggs of Cd9-deficient mice. Nat Genet. 2000; 24(3):279-82.

7. Claw KG, George RD, Swanson WJ. Detecting coevolution in mammalian sperm-egg fusion proteins. Mol Reprod Dev. 2014;81(6):531-8.

8. Bianchi E, Doe B, Goulding D, Wright GJ. Juno is the egg Izumo receptor and is essential for mammalian fertilization. Nature. 2014;508(7497):483-7.

9. Fujihara Y, Lu Y, Noda T, Oji A, Larasati T, Kojima-Kita K, et al. Spermatozoa lacking fertilization influencing membrane protein (FIMP) fail to fuse with oocytes in mice. P Natl Acad Sci USA. 2020;117(17):9393-400.

10. Chalbi M, Barraud-Lange V, Ravaux B, Howan K, Rodriguez N, Soule P, et al. Binding of sperm protein Izumol and its egg receptor Juno drives $\mathrm{Cd} 9$ accumulation in the intercellular contact area prior to fusion during mammalian fertilization. Development. 2014;141(19):3732-9.

11. Bianchi E, Wright GJ. Izumo meets Juno: preventing polyspermy in fertilization. Cell Cycle. 2014;13(13):2019-20.

12. Aydin H, Sultana A, Li S, Thavalingam A, Lee JE. Molecular architecture of the human sperm IZUMO1 and egg JUNO fertilization complex. Nature. 2016:534(7608):562-5.

13. Kim E, Kim JS, Lee Y, Song BS, Sim BW, Kim SU, et al. Molecular cloning, characterization of porcine IZUMO1, an IgSF family member. Reprod Domest Anim. 2013;48(1):90-7.

14. Xing WJ, Han BD, Wu Q, Zhao L, Bao XH, Bou S. Molecular cloning and characterization of Izumol gene from sheep and cashmere goat reveal alternative splicing. Mol Biol Rep. 2011;38(3):1995-2006.

15. Pan ZY, Li SD, Liu QY, Wang Z, Zhou ZK, Di R, et al. Whole-genome sequences of 89 Chinese sheep suggest role of RXFP2 in the development of unique horn phenotype as response to semi-feralization. Gigascience. 2018;7(4):giy019

16. Picelli S, Bjorklund AK, Faridani OR, Sagasser S, Winberg G, Sandberg R. Smart-seq2 for sensitive full-length transcriptome profiling in single cells. Nat Methods. 2013;10(11):1096-8.

17. Hu W, Dong X, Tian Z, Tang J, Liu Q, Wang X, et al. Polymorphism of Izumo1 gene and its association with litter size in sheep (Ovis aries). J China Agri Uni. 2020;25(1):95-104. 
18. Kato K, Satouh Y, Nishimasu H, Kurabayashi A, Morita J, Fujihara Y, et al. Structural and functional insights into IZUMO1 recognition by JUNO in mammalian fertilization. Nat Commun. 2016;7:12198.

19. Liang SC, Moskalenko M, Van Roey M, Jooss K. Depletion of regulatory T cells by targeting folate receptor 4 enhances the potency of a GM-CSFsecreting tumor cell immunotherapy. Clin Immunol. 2013;148(2):287-98.

20. Teng MW, Swann JB, von Scheidt B, Sharkey J, Zerafa N, McLaughlin N, et al. Multiple antitumor mechanisms downstream of prophylactic regulatory Tcell depletion. Cancer Res. 2010;70(7):2665-74.

21. Yamaguchi T, Hirota K, Nagahama K, Ohkawa K, Takahashi T, Nomura T, et al. Control of immune responses by antigen-specific regulatory $T$ cells expressing the folate receptor. Immunity. 2007;27(1):145-59.

22. Jiang Y, Xie M, Chen WB, Talbot R, Maddox JF, Faraut T, et al. The sheep genome illuminates biology of the rumen and lipid metabolism. Science. 2014:344(6188):1168-73.

23. Liu Q, Pan Z, Wang X, Hu W, Di R, Yao Y, et al. Progress on major genes for high fecundity in ewes. Front Agri Sci Eng. 2014;1 (4):282.

24. Pulkki MM, Mottershead DG, Pasternack AH, Muggalla P, Ludlow $H$, van Dinther $\mathrm{M}$, et al. A covalently Dimerized recombinant human bone morphogenetic Protein-15 variant identifies bone morphogenetic protein receptor type $1 \mathrm{~B}$ as a key cell surface receptor on ovarian Granulosa cells. Endocrinology. 2012;153(3):1509-18.

25. Peng J, Li QL, Wigglesworth K, Rangarajan A, Kattamuri C, Peterson RT, et al. Growth differentiation factor 9:bone morphogenetic protein 15 heterodimers are potent regulators of ovarian functions. P Natl Acad Sci USA. 2013;110(8):E776-85.

26. Juengel JL, Davis GH, McNatty KP. Using sheep lines with mutations in single genes to better understand ovarian function. Reproduction. 2013; 146(4):R111-23.

27. Satouh YIN, Ikawa M, Okabe M. Visualization of the moment of mouse sperm-egg fusion and dynamic localization of IZUMO1. J Cell Sci. 2012; 125(Pt 21):4985-90.

28. Ohto U, Ishida H, Krayukhina E, Uchiyama S, Inoue N, Shimizu T. Structure of IZUMO1-JUNO reveals sperm-oocyte recognition during mammalian fertilization. Nature. 2016:534(7608):566-9.

29. Inoue N, Hagihara Y, Wright D, Suzuki T, Wada I. Oocyte-triggered dimerization of sperm IZUMO1 promotes sperm-egg fusion in mice. Nat Commun. 2015;6:8858

30. Klinovska K, Sebkova N, Dvorakova-Hortova K. Sperm-egg fusion: a molecular enigma of mammalian reproduction. Int J Mol Sci. 2014;15(6): 10652-68.

31. Yu M, Zhao H, Chen T, Tian Y, Li M, Wu K, et al. Mutational analysis of IZUMO1R in women with fertilization failure and polyspermy after in vitro fertilization. J Assist Reprod Genet. 2018:35(3):539-44.

Ready to submit your research? Choose BMC and benefit from:

- fast, convenient online submission

- thorough peer review by experienced researchers in your field

- rapid publication on acceptance

- support for research data, including large and complex data types

- gold Open Access which fosters wider collaboration and increased citations

- maximum visibility for your research: over $100 \mathrm{M}$ website views per year

At $\mathrm{BMC}$, research is always in progress.

Learn more biomedcentral.com/submissions 